\title{
Towards improved practices in Life Cycle Assessment of seafood and other aquatic products
}

\author{
Angel Avadí ${ }^{1,2} \cdot$ Patrik J. G. Henriksson ${ }^{3,4} \cdot$ lan Vázquez-Rowe ${ }^{5} \cdot$ Friederike Ziegler $^{6}$
}

Received: 11 February 2018 / Accepted: 16 February 2018 / Published online: 21 March 2018

(C) Springer-Verlag GmbH Germany, part of Springer Nature 2018

\section{Introduction}

Aquatic supply chains, based on e.g. fish, molluscs, crustaceans and algae, provide products aimed for direct or indirect human consumption and other uses. Global demand for these products is increasing, but the fact that wild-capture fisheries - supplying inputs for the food and feed industries - have stagnated (FAO 2016), or even declined (Pauly and Zeller 2016), has raised questions about the environmental consequences of aquatic supply chains (Ziegler et al. 2016). Research applying LCA to seafood products has emerged since the early years of the century and, until today, dozens of case studies of fisheries and aquaculture systems from all around the world have been published. The body of literature in this field has grown to the extent of allowing systematic reviews to be undertaken on specific production sectors, such as for capture fisheries (Vázquez-Rowe et al. 2012; Avadí and Fréon 2013) and aquaculture (Henriksson et al. 2012).

The lifecycle of seafood commodities differs from that of terrestrial production systems in their diversity, in the

Ian Vázquez-Rowe

ian.vazquez@pucp.pe

1 CIRAD, UPR Recyclage et Risque, 34398 Montpellier, France

2 Recyclage et Risque, CIRAD, University of Montpellier, Montpellier, France

3 Stockholm Resilience Centre, Stockholm University, Kräftriket 2B, 10691 Stockholm, Sweden

4 WorldFish, 11960 Bayan Lepas, Penang, Malaysia

5 Peruvian LCA Network, Department of Engineering, Pontificia Universidad Católica del Perú, Avenida Universitaria 1801, San Miguel, 15088 Lima, Peru

6 Agrifood and Bioscience, RISE Research Institutes of Sweden, PO Box 5401, 40229 Gothenburg, Sweden case of fisheries, the reliance on extraction of a natural resource (fish stocks), their impacts on often unmapped ecosystems (e.g. seafloors and deep sea fish stocks) and the more complex trophic webs of aquatic ecosystems. To capture also these biotic and fisheries-specific impacts, an increasing number of fisheries and aquaculture LCAs apply novel impact categories such as biotic resource use and benthic ecosystems impacts. Aquaculture systems, in addition, often rely on feed resources from capture fisheries, agriculture and livestock, requiring extensive LCI models.

Among the existing aquaculture seafood LCA studies, there is a strong focus on salmonids aquaculture in Europe and North America. The globally largest aquaculture sector, carp farming in China, has, however, been poorly covered. Peruvian anchoveta, the world's largest fishery and the primary source of fishmeal and fish oil, was first modelled in 2014. Consequently, while the number of aquatic LCAs has steadily been increasing, the uniqueness of aquatic production chains and the diversity of species leave many inventories overlooked and some relevant impact categories unaddressed. In response, we initiated this Special Issue (SI), to supplement literature and highlight shortcomings. Thirteen articles were ultimately accepted in the SI.

\section{Thirteen contributions towards better practices}

As far as the editors were able to ascertain, this SI constitutes the first attempt to cluster a series of papers linked to seafood LCA. Eight of the accepted papers are linked to aquaculture production and aquafeed, whereas three manuscripts delved into the environmental impacts of marine fisheries. Two papers were not linked directly to the food sector, but rather to non-food high-value products obtained from marine fisheries. 


\subsection{Aquaculture production and aquafeeds}

Parker (2018) evaluates a vertically integrated salmon production system in Tasmania, encompassing feed and seed production, grow-out, processing and distribution. The impact of the use of animal by-product inputs in aquaculture feeds was explored, thus contributing to the on-going efforts of reducing aquaculture's dependence on wild fisheries. Silva et al. (2018) also compare the environmental performance of different aquaculture feed ingredients originating from four sources: fish processing by-products, Peruvian anchovy, poultry by-products and soy. Newton and Little (2018) also focus on salmonids, with an LCA of Scottish Atlantic salmon, mapping the environmental impacts geographically. Primary data are presented from six salmon farms in Scotland, as well as an international feed mill and a major processor.

Aubin et al. (2018) analysed blue mussel (Mytilus edulis) bouchot culture in the Mont-St Michel Bay in France. Their study focuses on the ability of bivalves to "extract nutrients from the environment by filtering water and producing shell" by analysing how these behaviours influence LCA modelling. In the assessment, the chemical composition of both mussel flesh and shell were analysed to calculate potential positive effects in two impact categories: climate change and eutrophication. Ray et al. (2018), on the contrary, suggest that bivalve shells ultimately result in net emissions of carbon dioxide $\left(\mathrm{CO}_{2}\right)$ in the biogenic process of formation of calcium carbonate, calcification. Their results suggest that actual GHG emissions of bivalve systems could be considerably larger than previously calculated.

A contribution by Abdou et al. (2018) sheds light on a less studied species and geographical location, farmed seabass and sea bream in Tunisia. A sample of 18 farms (out of 24 in the country) was classified into coherent types by means of Principal Component Analysis, and demonstrated a correlation between rearing practices and environmental impacts, identifying technical parameters to be improved towards reducing impacts. Another study set in the Mediterranean is Mendoza-Beltran et al. (2018) who mainly focus on methodological issues when comparing an integrated multi-trophic aquaculture (IMTA) with conventional aquaculture production of seabass, sea bream, and oysters. Their results point towards slightly lower emissions in IMTA systems, but featuring a strong influence from the type of allocation used. Interestingly, the authors include allocation as a source of uncertainty with the conclusion that "most uncertainty in the results is probably due to inventory data dispersion".

Last among the aquaculture-related studies, Järviö et al. (2018) set out to present an improved estimate of the carbon emissions from mangrove deforestation. The article revisits several land use and land-use change (LULUC) publications and identifies three driving processes for $\mathrm{CO}_{2}$ emissions from mangrove deforestation: land-use change carbon losses, continuing carbon losses (mainly through sediment loss), and missed potential carbon sequestration.

\subsection{Marine fisheries}

Villanueva-Rey et al. (2018) analysed a small-scale coastal driftnet (xeito) fishery for European pilchard (Sardina pilchardus). The study shows how LCA could be used to support more sustainable and holistic decision-making in fisheries policy. Also in Spain, Laso et al. (2018) evaluated the European anchovy fishery in the Bay of Biscay per vessel and per port, to identify any discrepancies in environmental impacts among local fleets and evaluate "the skipper effect".

Avadí et al. (2018) studied the fishery for Peruvian hake (Merluccius gayi) caught by mid-water trawls. Different fleet segments, based on holding capacity and engine power were analysed. More complete data could serve as a basis for optimisation efforts that would benefit both the economic and environmental performance of the fishery.

\subsection{Non-food aquatic products}

In a third group of papers, Barr and Landis (2018) and Muñoz et al. $(2018 \mathrm{a}, \mathrm{b})$ highlight the increasing use of marine resources beyond food and feed. Barr and Landis (2018) use LCA to compare the production of Omega-3 fatty acids (n-3), high protein feed, and biofuel from Gulf Menhaden and algae. Results point towards the importance of using membrane filtration when algae are used as feedstock. Muñoz et al. (2018a, b), in the meantime, used consequential LCA modelling to evaluate the production of chitosan from shells originating from Indian wild-caught shrimp or snow crabs caught off Newfoundland (Canada). Results presented suggest that the two chitosan supply chains have different environmental profiles depending upon geographical location, raw material used, and final application.

\section{Conclusions}

The thirteen contributions to this SI present inventory data on many previously undescribed capture fisheries, farming systems, geographical regions, inventory flows, and supporting processes. They also introduce methodological advances in the form of statistical considerations, impact categories relevant to aquatic resources, and spatial considerations. We therefore see this SI as a valuable contribution to the field of aquatic LCA research.

Considerable effort has been put in the collection of seafood LCA inventory data over the last decade. The use of these beyond individual case studies is unfortunately hampered either because they are not published at all or not available in sufficient detail. Future efforts should therefore aim at 
collecting data on a more diverse set of countries and systems, and to report these in a suitable format. Recent initiatives, by ecoinvent ${ }^{\circledR}$ to collect inventory data from Latin American fisheries- and aquaculture-related production systems and the initiative to develop a seafood LCI database linked to the development of EU Product Environmental Footprinting are steps in the right direction.

Biotic resource use was identified as the best-explored impact category specific to seafood LCAs. Better data are, however, needed to support this and other impact categories relevant to aquatic environments. In terms of methodological choices, allocation remains the major rift. The use of contrasting allocation strategies would therefore increase comparability among results and allow for stronger conclusions (e.g. if product A consistently presents lower impacts than product $B$ regardless of which allocation method is used). Adopting quantitative uncertainty approaches in LCI data, characterisation factors, and/or methodological choices (e.g. allocation) would add additional statistical confidence to support conclusions (Henriksson et al. 2015). Important to highlight here is that impact assessment results from different studies are largely incomparable, given different assumptions and methodological choices. It is more feasible to compare critical inventory items such as fuel, water and chemicals use for individual processes (e.g. fishing or grow-out), which can be contrasted per functional unit.

Acknowledgements The editing committee warmly thanks all contributors to this Special Issue, as well as Mary Ann Curran for her support in the preparation of the issue.

\section{Compliance with ethical standards}

Conflict of interest The authors declare that they have no conflicts of interest.

\section{References}

Abdou K, Lasram FBR, Romdhane MS, Le Loc'h F, Aubin J (2018) Rearing performances and environmental assessment of sea cage farming in Tunisia using life cycle assessment (LCA) combined with PCA and HCPC. Int J Life Cycle Assess. https://doi.org/10. 1007/s11367-017-1339-2 (this issue)

Aubin J, Fontaine C, Callier M, Roque d'Orbcastel E (2018) Blue mussel (Mytilus edulis) bouchot culture in Mont-St Michel Bay: potential mitigation effects on climate change and eutrophication. Int J Life Cycle Assess. https://doi.org/10.1007/s11367-017-1403-y (this issue)

Avadí A, Fréon P (2013) Life cycle assessment of fisheries: A review for fisheries scientists and managers. Fish Res 143:21-38

Avadí A, Adrien R, Aramayo V, Fréon P (2018) Environmental assessment of the Peruvian industrial hake fishery with LCA. Int J Life Cycle Assess. https://doi.org/10.1007/s11367-017-1364-1 (this issue)

Barr WJ, Landis AE (2018) Comparative life cycle assessment of a commercial algal multiproduct biorefinery and wild caught fishery for small pelagic fish. Int J Life Cycle Assess. https://doi.org/10.1007/ s11367-017-1395-7 (this issue)

FAO (2016) The state of world fisheries and aquaculture 2016. Rome, Italy Retrieved from: http://www.fao.org/3/a-i5555e.pdf. Latest access: February 11th 2018

Henriksson PJG, Guinée JB, Kleijn R, De Snoo GR (2012) Life cycle assessment of aquaculture systems - a review of methodologies. Int J Life Cycle Assess 17:304-313

Henriksson PJG, Heijungs R, Dao HMM, Phan LT, de Snoo GR, Guinée JB (2015) Product carbon footprints and their uncertainties in comparative decision contexts. PLoS One 10(3):e0121221

Järviö N, Henriksson PJ, Guinée JB (2018) Including GHG emissions from mangrove forests LULUC in LCA: a case study on shrimp farming in the Mekong Delta. Vietnam Int J Life Cycle Assess. https://doi.org/10.1007/s11367-017-1332-9 (this issue)

Laso J, Vázquez-Rowe I, Margallo M, Crujeiras RM, Irabien Á, Aldaco R (2018) Life cycle assessment of European anchovy (Engraulis encrasicolus) landed by purse seine vessels in northern Spain. Int J Life Cycle Assess. https://doi.org/10.1007/s11367-017-1318-7 (this issue)

Mendoza-Beltran A, Chiantore M, Pecorino D, Corner RA, Ferreira JG, Cò R, Guinée JB (2018) Accounting for inventory data and methodological choice uncertainty in a comparative life cycle assessment: the case of integrated multi-trophic aquaculture in an offshore Mediterranean enterprise. Int J Life Cycle Assess. https://doi.org/ 10.1007/s11367-017-1363-2 (this issue)

Muñoz I, Rodríguez C, Gillet D, Moerschbacher BM (2018a) Life cycle assessment of chitosan production in India and Europe. Int $\mathrm{J}$ Life Cycle Assess. https://doi.org/10.1007/s11367-017-1290-2 (this issue)

Muñoz I, Rodríguez C, Gillet D, Moerschbacher BM (2018b) Erratum to: Life cycle assessment of chitosan production in India and Europe. Int J Life Cycle Assess. https://doi.org/10.1007/s11367-017-1357-0 (this issue)

Newton RW, Little DC (2018) Mapping the impacts of farmed Scottish salmon from a life cycle perspective. Int J Life Cycle Assess. https:// doi.org/10.1007/s11367-017-1386-8 (this issue)

Parker R (2018) Implications of high animal by-product feed inputs in life cycle assessments of farmed Atlantic salmon. Int J Life Cycle Assess. https://doi.org/10.1007/s11367-017-1340-9 (this issue)

Pauly D, Zeller D (2016) Catch reconstructions reveal that global marine fisheries catches are higher than reported and declining. Nat Commun 7:10244

Ray NE, O'Meara T, Wiliamson T, Izursa JL, Kangas PC (2018) Consideration of carbon dioxide release during shell production in LCA of bivalves. Int J Life Cycle Assess. https://doi.org/10.1007/ s11367-017-1394-8 (this issue)

Silva CB, Valente LM, Matos E, Brandão M, Neto B (2018) Life cycle assessment of aquafeed ingredients. Int J Life Cycle Assess. https:// doi.org/10.1007/s11367-017-1414-8 (this issue)

Vázquez-Rowe I, Hospido A, Moreira MT, Feijoo G (2012) Best practices in life cycle assessment implementation in fisheries. Improving and broadening environmental assessment for seafood production systems. Trends Food Sci Technol 28:116-131

Villanueva-Rey P, Vázquez-Rowe I, Arias A, Moreira MT, Feijoo G (2018) The importance of using life cycle assessment in policy support to determine the sustainability of fishing fleets: a case study for the small-scale xeito fishery in Galicia. Spain Int J Life Cycle Assess. https://doi.org/10.1007/s11367-017-1402-z (this issue)

Ziegler F, Hornborg S, Green BS, Eigaard OR, Farmery AK, Hammar L, Hartmann K, Molander S, Parker RWR, Skontorp Hognes E, Vázquez-Rowe I, Smith ADM (2016) Expanding the concept of sustainable seafood using life cycle assessment. Fish Fish 17: 1073-1093 